\title{
Inappropriate direct oral anticoagulant dosing in atrial fibrillation patients is associated with prescriptions for outpatients rather than inpatients: a single- center retrospective cohort study
}

Motoyasu Miyazaki ${ }^{1 *}$, Koichi Matsuo', Masanobu Uchiyama', Yoshihiko Nakamura², Yuya Sakamoto', Momoko Misaki ${ }^{1}$, Kaoko Tokura', Shiro Jimi ${ }^{3}$, Keisuke Okamura ${ }^{4}$, Sen Adachi ${ }^{4}$, Tomohiko Yamamoto ${ }^{4}$, Kazuyuki Shirai ${ }^{4}$, Hidenori Urata ${ }^{4}$ and Osamu Imakyure ${ }^{1}$

\begin{abstract}
Background: Inappropriate dosing of direct oral anticoagulants (DOACs) has been associated with clinical safety and efficacy; however, little is known about clinical data associated with an inappropriate DOAC dosing in Japan. In addition, there is no report in which the appropriateness of DOAC dosing between prescription for inpatients and for outpatients was examined. In this study, we aimed to investigate the prevalence and factors associated in the inappropriate dosing of DOACs in patients with atrial fibrillation (AF).

Methods: The retrospective cohort study was conducted at a single Japanese university hospital. Both inpatients and outpatients, who were diagnosed with AF and for whom treatment with either dabigatran, rivaroxaban, apixaban, or edoxaban was initiated between April 1, 2014 and March 31, 2018, were enrolled in the study. Appropriateness of DOAC dosing was assessed according to the manufacturer's labeling recommendations (dose reduction criteria) of each DOAC. Inappropriate reduced dose, namely, underdosing, was defined as prescription of a reduced dose of DOAC despite the patient not meeting the dose reduction criteria. Inappropriate standard dose, namely, overdosing, was defined as prescription of a standard dose of DOAC despite the patient meeting the dose reduction criteria. Inappropriate DOAC dosing was defined as a deviation of the recommended dose (both underdosing and overdosing).

Results: A total of 316 patients (dabigatran, 28; rivaroxaban, 107; apixaban, 116; and edoxaban, 65) were included, with a median (interquartile range) age of 75 (66-81) years and $62.3 \%$ male. DOACs were prescribed at an appropriate standard dose in $39.2 \%$ of patients, an appropriate reduced dose in $36.7 \%$, an inappropriate standard dose in 2.5\%, and an inappropriate reduced dose in 19.3\%. Multivariate analysis revealed that the inappropriate dosing of DOACs was significantly associated with prescriptions for outpatients (vs. inpatients; odds ratio [OR] 2.87, 95\% confidence interval $[\mathrm{Cl}] 1.53-5.62, p<0.001)$ and those with higher HAS-BLED scores (OR 1.87, 95\% Cl 1.42$2.51, p<0.001)$.

(Continued on next page)
\end{abstract}

\footnotetext{
* Correspondence: motoyasu@fukuoka-u.ac.jp

${ }^{1}$ Department of Pharmacy, Fukuoka University Chikushi Hospital, Fukuoka

Japan; 1-1-1, Zokumyoin, Chikushino-shi, Fukuoka 818-8502, Japan

Full list of author information is available at the end of the article
}

(c) The Author(s). 2020 Open Access This article is distributed under the terms of the Creative Commons Attribution 4.0 International License (http://creativecommons.org/licenses/by/4.0/), which permits unrestricted use, distribution, and reproduction in any medium, provided you give appropriate credit to the original author(s) and the source, provide a link to the Creative Commons license, and indicate if changes were made. The Creative Commons Public Domain Dedication waiver (http://creativecommons.org/publicdomain/zero/1.0/) applies to the data made available in this article, unless otherwise stated. 
(Continued from previous page)

Conclusions: Our results demonstrated that the inappropriate dosing of DOACs occurred in approximately $20 \%$ of AF patients, and was more frequent in outpatients (vs. inpatients) and in those with a higher risk of bleeding. It is recommended that pharmacists play a greater role in assisting in the prescription process to help physicians make better decisions.

Keywords: Direct oral anticoagulant, Inappropriate dose, Prescription, Outpatient,

\section{Background}

Atrial fibrillation (AF) is the most common serious arrhythmia and an important risk factor of cardiogenic stroke. In Japan, the prevalence of AF is predicted to increase to $\geq 1 \%$ of the Japanese population by 2050 [1]. Until recently, warfarin was the only agent used to prevent stroke in AF patients. However, since 2011, the direct oral anticoagulants (DOACs) dabigatran, rivaroxaban, apixaban, and edoxaban have been approved for anticoagulant therapy in Japan. A meta-analysis of randomized clinical trials has shown the benefit of DOAC therapy in reducing the incidence of stroke, intracranial hemorrhage, and mortality among AF patients, compared with the use of warfarin [2]. In addition, anticoagulant regimens involving warfarin are generally under-prescribed by physicians because of the fear of increased bleeding $[3,4]$. In contrast, DOACs have fixed dose regimens and do not require frequent dose adjustments or routine pharmacodynamic monitoring, including the prothrombin time-international normalized ratio (PT-INR). However, the dosing of these drugs should be appropriately adjusted based on one or more clinical features such as renal function, age, body weight, and concomitant drug use. In Japan, the prescription dose for each DOAC is determined by the manufacturer's recommendations in the drug package insert, and the physician's prescription is usually audited by pharmacists; however, physicians occasionally prescribe inappropriate doses of DOACs in real-world clinical settings [5-7]. Because few hospitals in Japan describe clinical laboratory data for out-of-hospital prescriptions, proper dosing adjustments may not be performed with prescriptions for outpatients compared with those for inpatients [8]. However, to date, little is known in Japan about clinical factors associated with an inappropriate DOAC dosing, including whether it is prescribed for inpatients or outpatients. The inappropriate dosing of DOACs has been associated with clinical safety and efficacy $[6,9]$. Therefore, it is essential to clarify the factors associated with the inappropriate dosing of DOACs to better educate physicians and improve their correct use.
The aim of the present study was to examine the prevalence and associated factors related to the inappropriate dosing of DOACs in AF patients at a single Japanese center.

\section{Methods \\ Setting and study population}

This retrospective cohort pilot study was conducted at a single Japanese university hospital. We included inpatients and outpatients attending the Department of Cardiovascular Diseases who were diagnosed with $\mathrm{AF}$ and for whom treatment with either dabigatran, rivaroxaban, apixaban, or edoxaban was initiated between April 1, 2014 and March 31, 2018 (from fiscal year 2014 to 2017). Patients who were under 20 years old, for whom a DOAC was initiated for the treatment or prophylaxis of venous thromboembolism, or who had history of DOAC prescription prior to the study period, were excluded.

\section{Data collection}

We collected patient data when a DOAC was prescribed for the first time during the study period. Patient characteristics, clinical information, and prescription information after pharmacist's inquiries (if any) were obtained from electronic medical records. These characteristics included age, gender, height, body weight, body mass index, current smoking, and alcohol abuse. Clinical information included comorbidities (hypertension, heart failure, myocardial infarction, dyslipidemia, diabetes mellitus, cerebrovascular disease, and hepatitis) and baseline laboratory data. Creatinine clearance $(\mathrm{CrCl})$ was estimated using the Cockcroft and Gault formula [10]. History of bleeding, including gastrointestinal hemorrhage (GIH), was also obtained from the medical records. Patient prescription information included the following information: dosage and administration of DOAC; number of medicines; polypharmacy (number of oral medications $\geq 6$ ) [11]; concomitant drug use, particularly antiplatelet agents, P-glycoprotein inhibitors, and hepatic cytochrome P450 3A4 inhibitors; and a history of warfarin use. $\mathrm{CHADS}_{2}, \mathrm{CHA}_{2} \mathrm{DS}_{2}$-VASc, and HAS-BLED scores were calculated for each patient based on his or her clinical data at the time of initial DOAC prescription [12-14]. 


\section{DOAC dosing}

The appropriateness of DOAC dosing was assessed according to the recommendations of the drug package insert for each DOAC. We used certain dose reduction criteria, including renal function, age, body weight, concomitant drug use, and history of $\mathrm{GIH}$, as listed in Table 1. An inappropriate reduced dose, namely, underdosing, was defined as a prescription for a reduced dose of a DOAC despite the patient not meeting the dose reduction criteria. An inappropriate standard dose, namely, overdosing, was defined as a prescription for a standard dose of a DOAC despite the patient meeting the dose reduction criteria. An inappropriate DOAC dosing was defined as a deviation of the recommended dose (i.e., both underdosing and overdosing). An offlabel dose was defined as a dose not described in the drug insert package.

\section{Statistical analyses}

Binary variables were expressed as proportions and continuous variables were expressed as the medians and interquartile ranges (IQRs). Differences in the continuous variables among the four DOACs were evaluated using the Steel-Dwass test, with differences in categorical variables evaluated using the chi-squared test. Significance was adjusted for multiple comparisons using Bonferroni correction. To determine the factors associated with the inappropriate dosing of DOACs, comparisons between appropriate and inappropriate DOAC dosing groups were conducted by univariate analysis using the chi-squared test or Fisher's exact test (as appropriate) for proportions and the Mann-Whitney U test for medians. Factors that were significantly associated with the inappropriate dosing of DOACs in univariate analysis were included in multivariate logistic regression analysis via a stepwise procedure to identify risk factors that were independently associated with inappropriate dosing. A trend analysis for the appropriateness of DOAC dosing was performed using the Cochran-Armitage trend test. All statistical analyses were performed using JMP 14 (SAS Institute Inc., Cary, NC, USA), with a $p$ value $<0.05$ considered significant.

\section{Results}

\section{Baseline characteristics}

A total of 316 patients (118 inpatients and 198 outpatients) were included in this study, with a median (IQR) age of $75(66-81)$ years and $62.3 \%$ male. The demographic characteristics of the patients stratified by DOAC are listed in Table 2. Patients administered apixaban (median [IQR]: 79 [73-83] years) were older than those administered dabigatran (71 [65-80] years) and rivaroxaban (71 [65-79] years) $(p=0.434$ and $p<0.001$, respectively). In addition, median (IQR) $\mathrm{CrCl}$ was lower in patients administered apixaban $(51.3[40.1-64.7] \mathrm{mL} /$ $\mathrm{min})$ than in those administered dabigatran (64.4 [48.5$82.1] \mathrm{mL} / \mathrm{min})$ and rivaroxaban $(60.9[50.2-82.5] \mathrm{mL} /$ min) ( $p=0.079$ and $p=0.002$, respectively). Overall, 200 $(64.1 \%)$ of the 316 patients had a $\mathrm{CrCl} \geq 50 \mathrm{~mL} / \mathrm{min}$. There were no differences in comorbidities among the patients given the four DOACs. Overall, approximately $70 \%$ of patients presented with hypertension, greater than 30\% with heart failure and dyslipidemia, 25\% with diabetes mellitus, and greater than $10 \%$ with myocardial infarction and cerebrovascular disease. Ninety-two (29.1\%) of the 316 patients had a history of warfarin use and $79(25 \%)$ had concomitant antiplatelet drugs. The proportion of patients who smoked was higher in the rivaroxaban group (18.7\%) than in the apixaban group (6.9\%) $\quad(p=0.047)$. Median (IQR) $\quad \mathrm{CHADS}_{2}$ and $\mathrm{CHA}_{2} \mathrm{DS}_{2}$-VASc scores were higher in patients administered apixaban (2 [1-3] and 4 [3-5], respectively) than in those administered rivaroxaban $(1[1-3]$ and 3 [2-4], respectively) ( $p=0.006$ and $p=0.010$, respectively).

Table 1 Dose reduction criteria of dabigatran, rivaroxaban, apixaban, and edoxaban in our study

\begin{tabular}{|c|c|c|c|c|c|}
\hline & & Dabigatran & Rivaroxaban & Apixaban & Edoxaban \\
\hline \multicolumn{2}{|c|}{ Standard dose } & 150 mg twice daily & 15 mg once daily & 5 mg twice daily & 60 mg once daily \\
\hline \multicolumn{2}{|c|}{ Reduced dose } & 110 mg twice daily & 10 mg once daily & $2.5 \mathrm{mg}$ twice daily & 30 mg once daily \\
\hline \multirow{3}{*}{$\begin{array}{l}\text { Dose } \\
\text { reduction } \\
\text { criteria }\end{array}$} & $\begin{array}{l}\text { Renal } \\
\text { function }\end{array}$ & $\mathrm{CrCl} 30$ to $50 \mathrm{~mL} / \mathrm{min}$ & $\mathrm{CrCl} 15$ to $49 \mathrm{~mL} / \mathrm{min}$ & $\begin{array}{l}\geq 2 \text { of the following: Serum } \\
\text { creatinine } \geq 1.5 \mathrm{mg} / \mathrm{dL}\end{array}$ & $\mathrm{CrCl} 15$ to $50 \mathrm{~mL} / \mathrm{min}$ \\
\hline & Age & Age $\geq 70$ years & & Age $\geq 80$ years & \\
\hline & Body weight & & & Body weight $\leq 60 \mathrm{~kg}$ & Body weight $\leq 60 \mathrm{~kg}$ \\
\hline \multicolumn{2}{|c|}{ Concomitant drug use } & $\begin{array}{l}\text { P-gp inhibitors (quinidine, } \\
\text { verapamil, amiodarone, } \\
\text { tacrolimus, cyclosporine, } \\
\text { ritonavir, nelfinavir, } \\
\text { saquinavir) }\end{array}$ & $\begin{array}{l}\text { CYP } 3 \text { A4 and P-gp in- } \\
\text { hibitors (fluconazole, } \\
\text { fosfluconazole, clari- } \\
\text { thromycin, } \\
\text { erythromycin) }\end{array}$ & $\begin{array}{l}\text { CYP } 3 A 4 \text { and P-gp inhibitors } \\
\text { [Azole antifungal agents } \\
\text { (except for fluconazole)] } \\
\text { and HIV protease inhibitors] }\end{array}$ & $\begin{array}{l}\text { P-gp inhibitors (quinidine, verapamil, } \\
\text { cyclosporine, erythromycin, } \\
\text { azithromycin, clarithromycin, } \\
\text { itraconazole, diltiazem, amiodarone, } \\
\text { HIV protease inhibitors) }\end{array}$ \\
\hline & Other & History of GlH & & & \\
\hline
\end{tabular}


Table 2 Demographic characteristics of the patients stratified by direct oral anticoagulant

\begin{tabular}{|c|c|c|c|c|c|}
\hline Characteristics & Overall $(n=316)$ & Dabigatran $(n=28)$ & Rivaroxaban $(n=107)$ & Apixaban $(n=116)$ & Edoxaban $(n=65)$ \\
\hline Age in years, median (IQR) & $75(66-81)$ & $71(65-80)$ & $71(65-79)$ & $79(73-83)$ & $75(65-81)$ \\
\hline$<65$ & $57(18.0)$ & $6(21.4)$ & $24(22.4)$ & $13(11.2)$ & $14(21.5)$ \\
\hline $65 \leq-<70$ & $48(15.2)$ & $6(21.4)$ & $25(23.4)$ & $9(7.8)$ & $8(12.3)$ \\
\hline $70 \leq-<75$ & $46(14.6)$ & $3(10.7)$ & $16(15.0)$ & $18(15.5)$ & $9(13.8)$ \\
\hline $75 \leq-<80$ & 65 (20.6) & $6(21.4)$ & $16(15.0)$ & $26(22.4)$ & $17(26.2)$ \\
\hline $80 \leq$ & $100(31.6)$ & $7(25.0)$ & $26(24.3)$ & $50(43.1)$ & $17(26.2)$ \\
\hline Male gender & $197(62.3)$ & $22(78.6)$ & $72(67.3)$ & $67(57.8)$ & $36(55.4)$ \\
\hline Body weight in kg, median (IQR) & $59.4(50.6-68.0)^{c}$ & $61.6(54.6-66.5)^{\mathrm{a}}$ & $59.8(51.9-70.0)^{\mathrm{b}}$ & $57.7(47.3-66.3)^{\mathrm{a}}$ & $57.4(50.4-66.9)$ \\
\hline $\mathrm{BMI}$ in $\mathrm{kg} / \mathrm{m} 2$, median (IQR) & $23.0(20.9-25.0)^{d}$ & $22.9(21.7-25.6)^{\mathrm{a}}$ & $23.7(21.6-25.2)^{b}$ & $22.7(20.3-24.6)^{b}$ & $22.4(20.3-24.9)$ \\
\hline$<18.5$ & $24(7.7)$ & $1(3.7)$ & $3(2.9)$ & $13(11.4)$ & $7(10.8)$ \\
\hline $18.5 \leq-<25$ & $210(67.5)$ & $19(70.4)$ & $73(69.5)$ & $76(66.7)$ & $42(64.6)$ \\
\hline $25 \leq-<30$ & $67(21.5)$ & $7(25.9)$ & $26(24.8)$ & $19(16.7)$ & $15(23.1)$ \\
\hline $30 \leq$ & $10(3.2)$ & $0(0)$ & $3(2.9)$ & $6(5.3)$ & $1(1.5)$ \\
\hline \multicolumn{6}{|l|}{ Type of hospital visit } \\
\hline Inpatients & $118(37.3)$ & $5(17.9)$ & $32(29.9)$ & $51(44.0)$ & $30(46.2)$ \\
\hline Outpatients & $198(62.7)$ & $23(82.1)$ & $75(70.1)$ & $65(56.0)$ & $35(53.8)$ \\
\hline $\mathrm{CrCl}$ in $\mathrm{mL} / \mathrm{min}$, median (IQR) & $57.7(43.9-78.5)^{c}$ & $64.4(48.5-82.1)^{\mathrm{a}}$ & $60.9(50.2-82.5)^{\mathrm{b}}$ & $51.3(40.1-64.7)^{\mathrm{a}}$ & $60.8(43.3-94.4)$ \\
\hline $50 \leq$ & $200(64.1)$ & $19(70.4)$ & $80(76.2)$ & $61(53.0)$ & $40(61.5)$ \\
\hline $30 \leq-<50$ & $90(28.8)$ & $8(29.6)$ & $21(20.0)$ & $44(38.3)$ & $17(26.2)$ \\
\hline $15 \leq-<30$ & $21(6.7)$ & $0(0)$ & $3(2.9)$ & $10(8.7)$ & $8(12.3)$ \\
\hline$<15$ & $1(0.3)$ & $0(0)$ & $1(1.0)$ & $0(0)$ & $0(0)$ \\
\hline Alcohol abuse & $11(3.5)$ & $2(7.1)$ & $4(3.7)$ & $3(2.6)$ & $2(3.1)$ \\
\hline Smoking & $41(13.0)$ & $4(14.3)$ & $20(18.7)$ & $8(6.9)$ & $9(13.8)$ \\
\hline History of warfarin use & $92(29.1)$ & $10(35.7)$ & $29(27.1)$ & $40(34.5)$ & $13(20.0)$ \\
\hline History of bleeding & $42(13.3)$ & $4(14.3)$ & $13(12.1)$ & $19(16.4)$ & $6(9.2)$ \\
\hline History of GIH & $14(4.4)$ & $3(10.7)$ & $2(1.9)$ & $8(6.9)$ & $1(1.5)$ \\
\hline \multicolumn{6}{|l|}{ Comorbidities } \\
\hline Hypertension & $210(66.5)$ & $19(67.9)$ & $68(63.6)$ & $75(64.7)$ & $48(73.8)$ \\
\hline Heart failure & 99 (31.3) & $7(25.0)$ & $28(26.2)$ & $41(35.3)$ & $23(35.4)$ \\
\hline Myocardial infarction & $32(10.1)$ & $3(10.7)$ & $14(13.1)$ & $11(9.5)$ & $4(6.2)$ \\
\hline Dyslipidemia & $104(32.9)$ & $13(46.4)$ & $37(34.6)$ & $29(25.0)$ & $25(38.5)$ \\
\hline Diabetes mellitus & $79(25.0)$ & $8(28.6)$ & $24(22.4)$ & $31(26.7)$ & $16(24.6)$ \\
\hline Cerebrovascular disease & $41(13.0)$ & $3(10.7)$ & $11(10.3)$ & $19(16.4)$ & $8(12.3)$ \\
\hline Hepatitis & $17(5.4)$ & $0(0)$ & $7(6.5)$ & $5(4.3)$ & $5(7.7)$ \\
\hline Polypharmacy & $129(40.8)$ & $9(32.1)$ & $37(34.6)$ & $57(49.1)$ & $26(40.0)$ \\
\hline \multicolumn{6}{|l|}{ Concomitant drug use } \\
\hline Antiplatelet drug & $79(25.0)$ & $3(10.7)$ & $36(33.6)$ & $25(21.6)$ & $15(23.1)$ \\
\hline SAPT & $55(17.4)$ & $2(7.1)$ & $27(25.2)$ & $16(13.8)$ & $10(15.4)$ \\
\hline DAPT & $13(4.1)$ & $1(3.6)$ & $4(3.7)$ & $4(3.4)$ & $4(6.2)$ \\
\hline Non-SAPT/DAPT & $17(5.4)$ & $0(0)$ & $9(8.4)$ & $6(5.2)$ & $2(3.1)$ \\
\hline NSAIDs & $4(1.3)$ & $0(0)$ & $1(0.9)$ & $2(1.7)$ & $1(1.5)$ \\
\hline Amiodarone & $11(3.5)$ & $2(7.1)$ & $1(0.9)$ & $4(3.4)$ & $4(6.2)$ \\
\hline Verapamil & $4(1.3)$ & $0(0)$ & $4(3.7)$ & $0(0)$ & $0(0)$ \\
\hline Diltiazem & $11(3.5)$ & $1(3.6)$ & $2(1.9)$ & $7(6.0)$ & $1(1.5)$ \\
\hline
\end{tabular}


Table 2 Demographic characteristics of the patients stratified by direct oral anticoagulant (Continued)

\begin{tabular}{llllll}
\hline Characteristics & Overall $(n=316)$ & Dabigatran $(n=28)$ & Rivaroxaban $(n=107)$ & Apixaban $(n=116)$ & Edoxaban $(n=65)$ \\
\hline CHADS $_{2}$ score, median (IQR) & $2(1-3)$ & $2(1-3)$ & $1(1-3)$ & $2(1-3)$ & $2(1-3)$ \\
$0-1$ & $123(38.9)$ & $12(42.9)$ & $56(52.3)$ & $33(28.4)$ & $22(33.8)$ \\
$\geq 2$ & $193(61.1)$ & $16(57.1)$ & $51(47.7)$ & $83(71.6)$ & $43(66.2)$ \\
CHA $_{2}$ DS $_{2}$-VASC score, median (IQR) & $3(2-5)$ & $3(2-4)$ & $3(2-4)$ & $4(3-5)$ & $4(2-5)$ \\
$0-1$ & $46(14.6)$ & $4(14.3)$ & $24(22.4)$ & $9(7.8)$ & $9(13.8)$ \\
$2-3$ & $115(36.4)$ & $13(46.4)$ & $41(38.3)$ & $40(34.5)$ & $21(32.3)$ \\
$\geq 4$ & $155(49.1)$ & $11(39.3)$ & $42(39.3)$ & $67(57.8)$ & $35(53.8)$ \\
HAS-BLED score, median (IQR) & $2(1-2)$ & $2(1-2)$ & $2(1-2)$ & $2(1-2)$ & $1(1-2)$ \\
$0-2$ & $252(79.7)$ & $27(96.4)$ & $85(79.4)$ & $89(76.7)$ & $51(78.5)$ \\
$\geq 3$ & $64(20.3)$ & $1(3.6)$ & $22(20.6)$ & $27(23.3)$ & $14(21.5)$
\end{tabular}

Missing data: ${ }^{a} \mathrm{n}-1,{ }^{b} \mathrm{n}-2,{ }^{\mathrm{c}} \mathrm{n}-4,{ }^{\mathrm{d}} \mathrm{n}-5$

Abbreviations: BMI, Body mass index; $C r C l$, Creatinine clearance; DAPT, Dual antiplatelet therapy; GIH, Gastrointestinal hemorrhage; IQR, Interquartile range; NSAID, Non-steroidal anti-inflammatory drug; $S A P T$, Single antiplatelet therapy

There were no significant differences in the HAS-BLED scores among the patients given the four DOACs.

\section{Appropriateness of DOAC dosing}

A total of 28 patients were prescribed dabigatran, 107 rivaroxaban, 116 apixaban, and 65 edoxaban (Fig. 1). The standard dose of the given DOAC was prescribed to 135 patients $(42.7 \%)$, with a reduced dose given to 178 patients (56.3\%). An off-label reduced dose was prescribed to one patient for dabigatran ( $75 \mathrm{mg}$ twice daily) and two patients for apixaban ( $2.5 \mathrm{mg}$ once daily). The use of a DOAC was contraindicated in only one patient for rivaroxaban, whose $\mathrm{CrCl}$ was $13.8 \mathrm{~mL} / \mathrm{min}$. The prescription rates of dabigatran and rivaroxaban have been significantly decreasing, with rates of 20.5 and $40.9 \%$ in $2014,4.4$ and $47.1 \%$ in $2015,3.7$ and $33.3 \%$ in 2016 , and 5.1 and $15.2 \%$ in 2017 , respectively $(p<0.001)$. In contrast the prescription rate of edoxaban has been significantly increasing, at $3.4 \%$ in $2014,2.9 \%$ in 2015 , 28.4\% in 2016, and 46.8\% in 2017 ( $\mathrm{p}<0.001$ ) (Fig. 2).

Of the 316 patients included in this study, the appropriateness of DOAC dosing could be assessed by using dose reduction criteria in 309 (97.8\%) patients. DOACs were prescribed at an appropriate standard dose in 124 (39.2\%) patients and at an appropriate reduced dose in $116(36.7 \%)$. Underdosing and overdosing occurred in

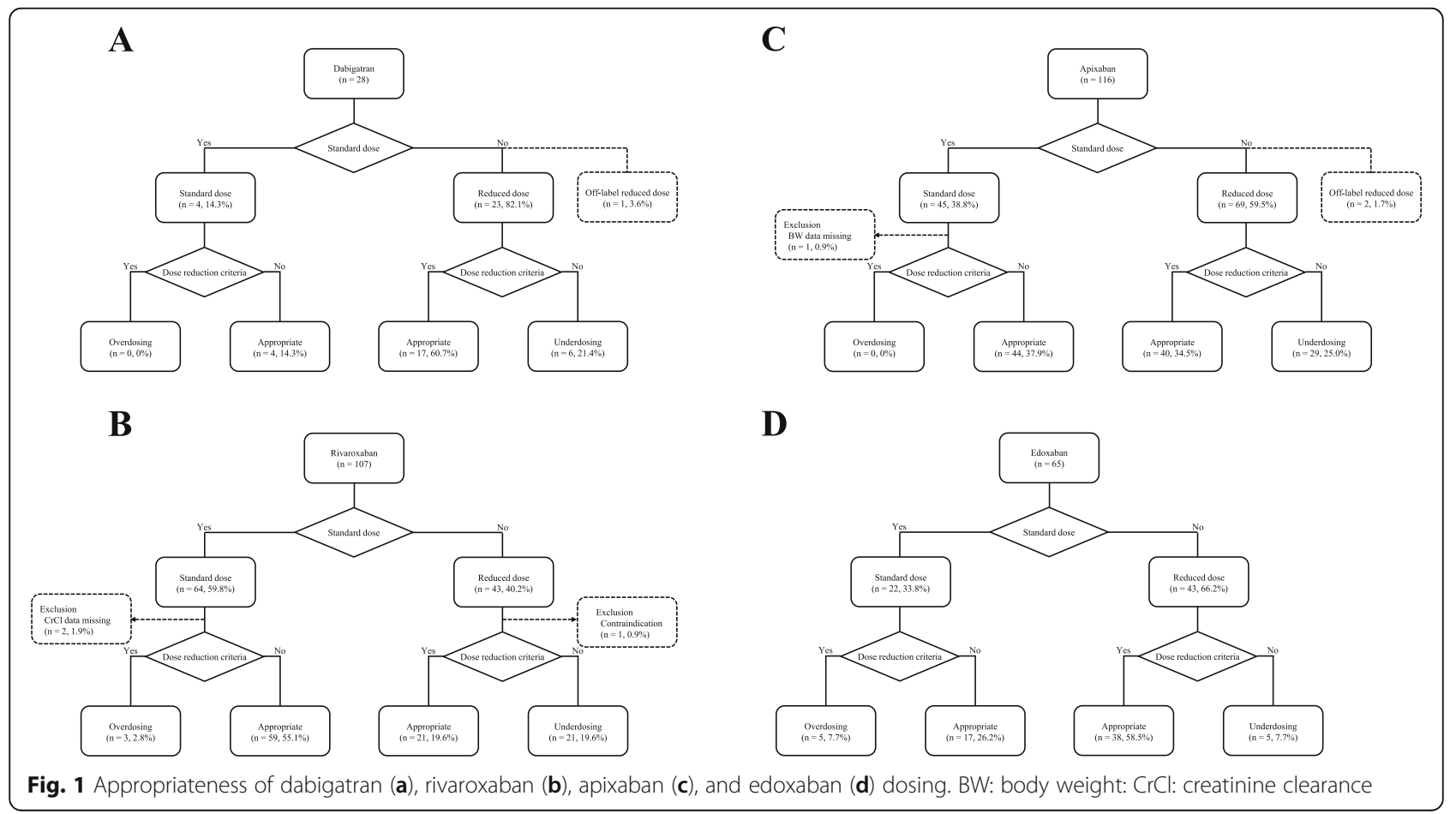




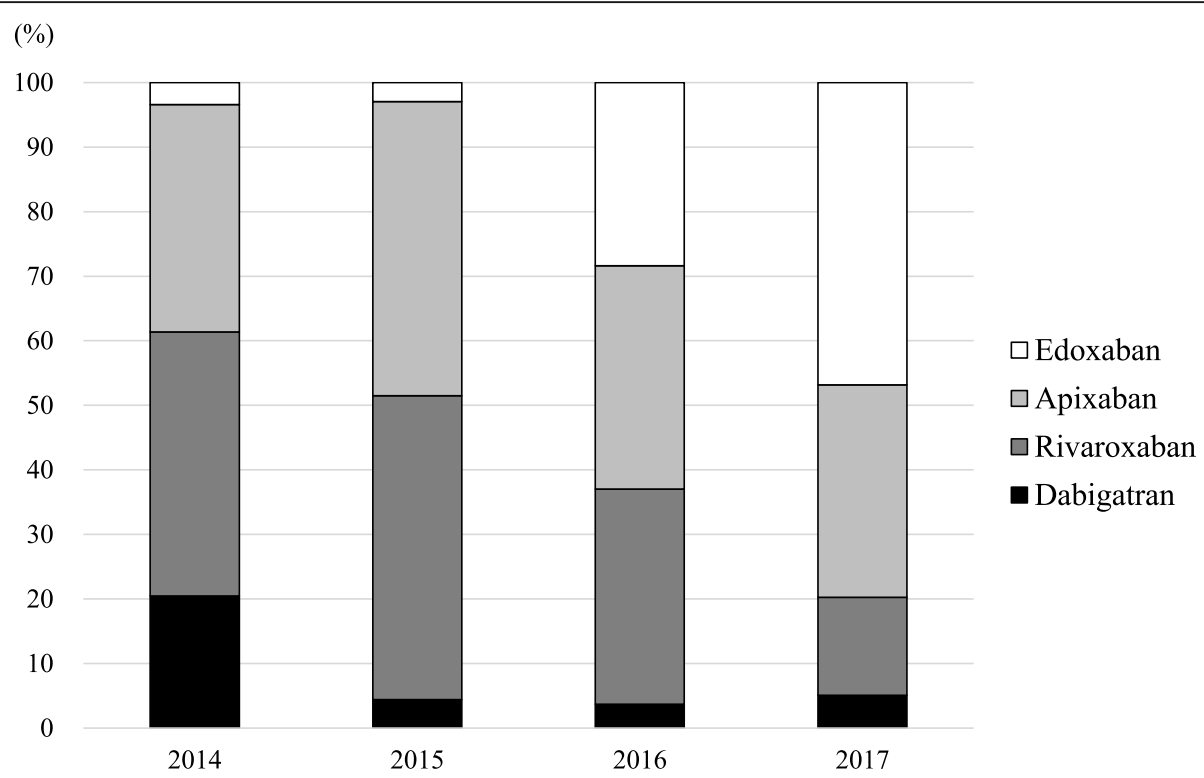

Fig. 2 Trends in direct oral anticoagulant prescriptions from fiscal year 2014 to 2017

19.3 and $2.5 \%$ of patients, respectively. The appropriateness for each DOAC is described in Fig. 1. For all four DOACs, underdosing occurred more frequently than overdosing. In addition, the prevalence of underdosing tended to be higher for apixaban than for the other three DOACs $(p=0.066)$, while it was significantly lower for edoxaban than for the other three DOACs $(p=0.003)$. The rates of the appropriate standard dose, appropriate reduced dose, underdosing, and overdosing for both inpatients and outpatients are shown in Fig. 3. The rate of underdosing was significantly higher in outpatients than that in inpatients $(24.1 \%$ vs. $12.7 \%, p=0.015)$, and that of appropriate reduced dose was significantly lower in outpatients than that in inpatients $(30.9 \%$ vs. $48.3 \%, p=$ 0.002). The appropriateness of DOAC dosing per fiscal year is shown in Fig. 4. The rate of underdosing appears to be significantly decreasing, with a rate of $34.1 \%$ in $2014,22.4 \%$ in $2015,15.4 \%$ in 2016 , and $6.3 \%$ in 2017 $(p<0.001)$. During the study period, a total of 20 cardiologists initiated DOAC therapy for at least one or more patients, and we evaluated the appropriateness of DOAC dosing for 12 physicians who initiated DOAC therapy

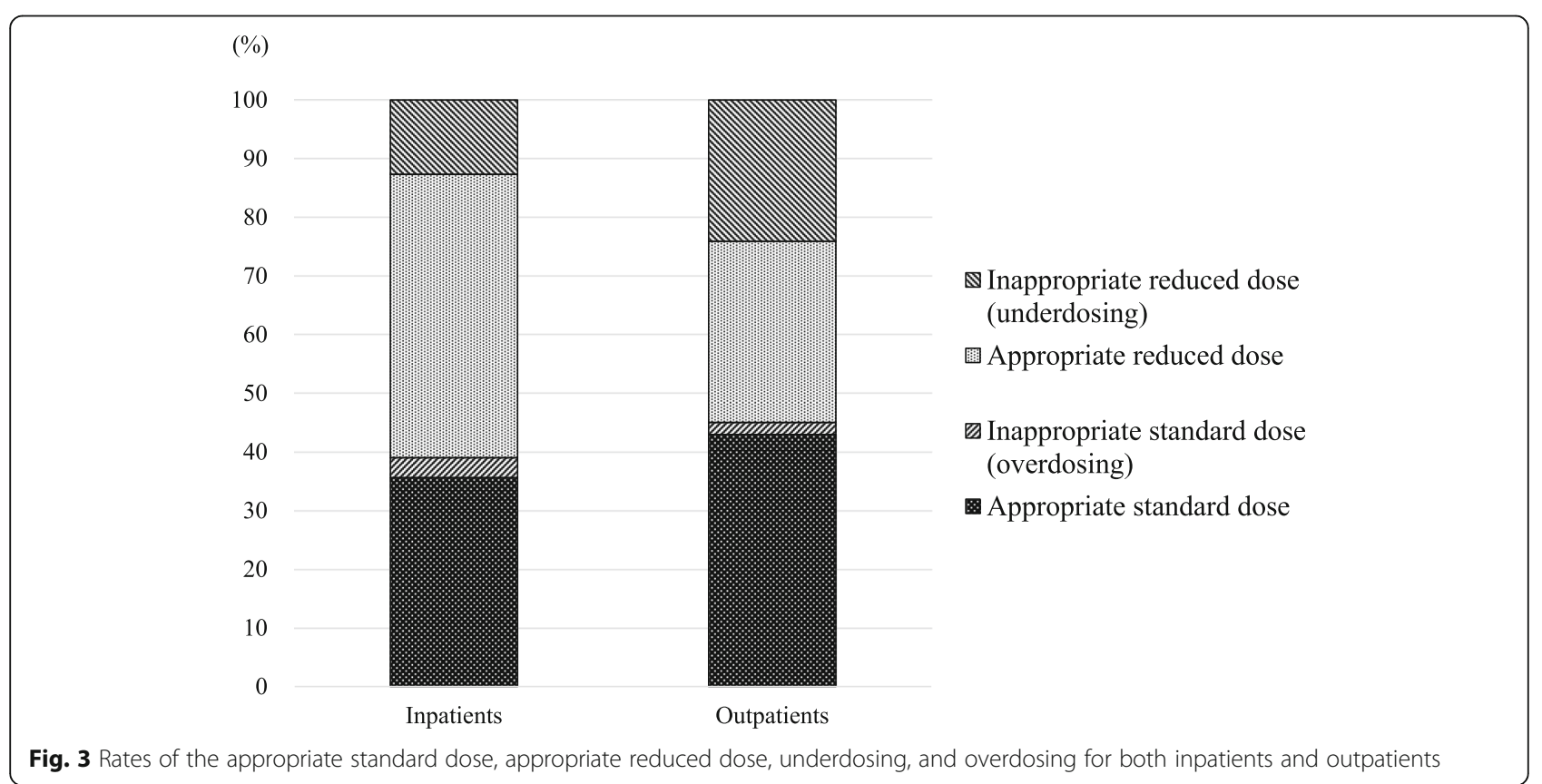




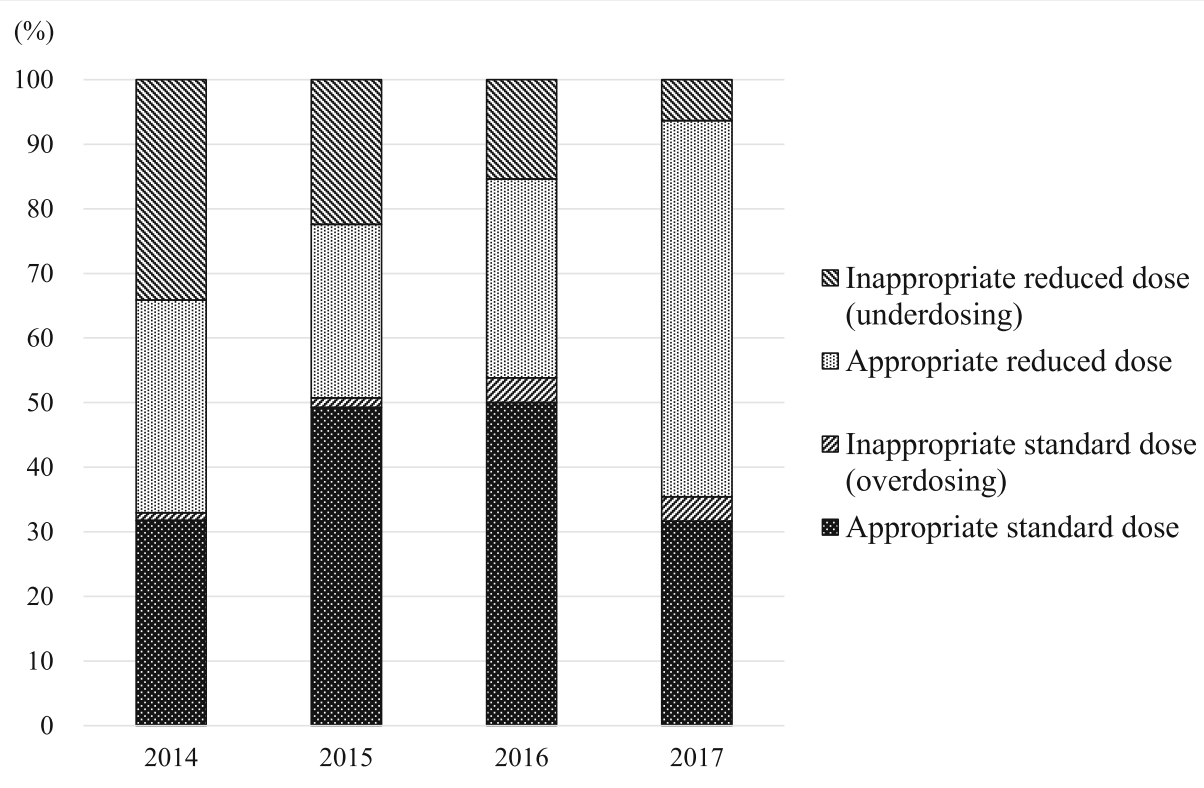

Fig. 4 Trends in the appropriateness of direct oral anticoagulant dosing from fiscal year 2014 to 2017

for more than 10 patients. The rate of underdosing varied among physicians, ranging from 0 to $45.5 \%$, while overdosing ranged from 0 to $9.5 \%$ (Additional file 2: Figure S1).

\section{Determinants for inappropriate dosing of DOACs}

The clinical features associated with the appropriateness of DOAC dosing are listed in Table 3. Inappropriate doses of DOAC were prescribed at a significant higher rate in outpatients compared with inpatients $(72.5 \%$ vs. $58.8 \%, p=0.039)$. Patients prescribed an inappropriate dose of a DOAC had higher rates of myocardial infarction $(17.4 \%$ vs. $7.9 \%, p=0.021)$ and cerebrovascular disease $(20.3 \%$ vs. $10.8 \%, p=0.039)$ as comorbidities, along with higher median (IQR) $\mathrm{CHA}_{2} \mathrm{DS}_{2}$-VASc (4 [3-5] vs. 3 $[2-4], \mathrm{p}=0.021)$ and HAS-BLED $(2[1-3]$ vs. $1[1,2]$, $p<0.001)$ scores than those of patients administered an appropriate dose. Patients prescribed an inappropriate dose of DOAC tended to have a greater history of bleeding $(20.3 \%$ vs. $11.7 \%, p=0.066)$, polypharmacy $(50.7 \%$ vs. $37.9 \%, p=0.056$ ), and higher median (IQR) $\mathrm{CHADS}_{2}$ score $(2[1-3]$ vs. 2 [1-3], $p=0.052)$. In addition, these patients tended to receive single antiplatelet therapy (24.6\% vs. $15.4 \%, p=0.076)$ at a higher rate than those given an appropriate dose. The comparison of demographic characteristics among the four groups (i.e., underdosing, appropriate reduced dosing, overdosing, and appropriate standard dosing of DOACs) are listed in Additional file 1: Table S1.

Using multivariate analysis, we determined that the inappropriate dosing of DOACs was significantly associated with prescriptions for outpatients (vs. for inpatients; odds ratio [OR] 2.87, 95\% confidence interval [CI] 1.53-
5.62, $p<0.001$ ) and higher HAS-BLED score (OR 1.87, 95\% CI 1.42-2.51, p < 0.001) (Table 4).

\section{Discussion}

Although DOACs have made a significant contribution to anticoagulant therapy, the use of these drugs should still be carefully managed. In this study, we investigated the prevalence and factors associated with the inappropriate dosing of DOACs by cardiologists in a Japanese university hospital. The main findings of our study were that an inappropriate dose of DOACs was prescribed in $21.8 \%$ of patients, with underdosing $(19.3 \%)$ being more common than overdosing (2.5\%), and prescriptions for outpatients (vs. inpatients) and those with higher HASBLED scores were associated with inappropriate doses.

There are two large registries that show the prevalence of the inappropriate dosing of DOACs in Japan, namely, the Fushimi AF Registry [5] and the SAKURA AF Registry $[6,15]$. In the Fushimi AF Registry, 32.2\% (37/115) of dabigatran, $21.2 \%(47 / 222)$ of rivaroxaban, and $25.7 \%$ $(52 / 202)$ of apixaban users were prescribed an off-label under-dose (i.e., underdosing) [5]. The SAKURA AF Registry revealed that inappropriate doses of DOACs were prescribed in $26.2 \%$ patients (underdosing in $22.2 \%$ and overdosing in $4.0 \%$ of patients, respectively) $[6,15]$. Furthermore, a retrospective cohort study conducted at a single Japanese center showed that $22.6 \%$ of patients receiving DOACs were inappropriately prescribed, with $21.3 \%$ underdosed and $1.3 \%$ overdosed [7]. These results indicated that an inappropriate dose of a DOAC was prescribed in approximately 1 in 4 or $5 \mathrm{AF}$ patients in Japan, which is in accordance with our results. In contrast, the ORBIT-AF II Registry, a nationwide AF 
Table 3 Comparison of demographic characteristics between the appropriate and inappropriate dosing of direct oral anticoagulants

\begin{tabular}{|c|c|c|c|}
\hline Characteristics & Appropriate dosing $(n=240)$ & Inappropriate dosing $(n=69)$ & $P$ value* \\
\hline Age in year, median (IQR) & $75(66-82)$ & $75(67-79)$ & 0.710 \\
\hline Male gender & $146(60.8)$ & $46(66.7)$ & 0.379 \\
\hline Body weight in kg, median (IQR) & $57.7(50.0-69.0)^{\mathrm{a}}$ & $61.3(52.2-65.5)$ & 0.581 \\
\hline $\mathrm{BMI}$ in $\mathrm{kg} / \mathrm{m}^{2}$, median (IQR) & $22.9(20.8-24.9)^{\mathrm{a}}$ & $23.2(20.9-24.9)^{\mathrm{a}}$ & 0.616 \\
\hline Type of hospital visit & & & 0.039 \\
\hline Inpatients & $99(41.3)$ & $19(27.5)$ & \\
\hline Outpatients & $141(58.8)$ & $50(72.5)$ & \\
\hline $\mathrm{CrCl}$ in $\mathrm{mL} / \mathrm{min}$, median (IQR) & $58.4(42.4-81.0)^{\mathrm{a}}$ & $56.4(48.9-71.4)$ & 0.882 \\
\hline Alcohol abuse & $7(2.9)$ & $3(4.3)$ & $0.699^{* *}$ \\
\hline Smoking & $32(13.3)$ & $8(11.6)$ & 0.705 \\
\hline History of warfarin use & $66(27.5)$ & $24(34.8)$ & 0.241 \\
\hline History of bleeding & $28(11.7)$ & $14(20.3)$ & 0.066 \\
\hline History of GIH & $9(3.8)$ & $5(7.2)$ & $0.320^{* *}$ \\
\hline DOAC & & & 0.464 \\
\hline Dabigatran & $21(8.8)$ & $6(8.7)$ & \\
\hline Rivaroxaban & $80(33.3)$ & $24(34.8)$ & \\
\hline Apixaban & $84(35.0)$ & $29(42.0)$ & \\
\hline Edoxaban & $55(22.9)$ & $10(14.5)$ & \\
\hline \multicolumn{4}{|l|}{ Comorbidities } \\
\hline Hypertension & $157(65.4)$ & $49(71.0)$ & 0.385 \\
\hline Heart failure & $73(30.4)$ & $26(37.7)$ & 0.254 \\
\hline Myocardial infarction & $19(7.9)$ & $12(17.4)$ & 0.021 \\
\hline Dyslipidemia & 79 (32.9) & $24(34.8)$ & 0.772 \\
\hline Diabetes mellitus & $58(24.2)$ & 19 (27.5) & 0.569 \\
\hline Cerebrovascular disease & $26(10.8)$ & $14(20.3)$ & 0.039 \\
\hline Hepatitis & $12(5.0)$ & $3(4.3)$ & $>0.999^{* *}$ \\
\hline Polypharmacy & $91(37.9)$ & $35(50.7)$ & 0.056 \\
\hline \multicolumn{4}{|l|}{ Concomitant drug use } \\
\hline Antiplatelet drug & $55(22.9)$ & $22(31.9)$ & 0.1291 \\
\hline SAPT & $37(15.4)$ & $17(24.6)$ & 0.076 \\
\hline DAPT & $10(4.2)$ & $3(4.3)$ & $>0.999^{* *}$ \\
\hline Non-SAPT/DAPT & $11(4.6)$ & $4(5.8)$ & $0.751^{*}$ \\
\hline NSAIDs & $3(1.3)$ & $1(1.4)$ & $>0.999^{* *}$ \\
\hline Amiodarone & $8(3.3)$ & $3(4.3)$ & $0.714^{* *}$ \\
\hline Verapamil & $2(0.8)$ & $1(1.4)$ & $0.533^{* *}$ \\
\hline Diltiazem & $10(4.2)$ & $1(1.4)$ & $0.466^{* *}$ \\
\hline $\mathrm{CHADS}_{2}$, median (IQR) & $2(1-3)$ & $2(1-3)$ & 0.052 \\
\hline $0-1$ & $98(40.8)$ & $21(30.4)$ & 0.118 \\
\hline$\geq 2$ & $142(59.2)$ & $48(69.6)$ & \\
\hline $\mathrm{CHA}_{2} \mathrm{DS}_{2}-\mathrm{VASC}$, median (IQR) & $3(2-4)$ & $4(3-5)$ & 0.021 \\
\hline $0-1$ & $40(16.7)$ & $3(4.3)$ & 0.0312 \\
\hline $2-3$ & $87(36.3)$ & $27(39.1)$ & \\
\hline$\geq 4$ & $113(47.1)$ & $39(56.5)$ & \\
\hline HAS-BLED, median (IQR) & $1(1-2)$ & $2(1-3)$ & $<0.001$ \\
\hline
\end{tabular}


Table 3 Comparison of demographic characteristics between the appropriate and inappropriate dosing of direct oral anticoagulants (Continued)

\begin{tabular}{clll}
\hline Characteristics & Appropriate dosing $(n=240)$ & Inappropriate dosing $(n=69)$ & P value \\
\hline $0-2$ & $198(82.5)$ & $49(71.0)$ & 0.036 \\
$\geq 3$ & $42(17.5)$ & $20(29.0)$ & \\
\hline
\end{tabular}

Missing data: ${ }^{a} \mathrm{n}-1$

Abbreviations: $B M I$, Body mass index; $C r C l$, Creatinine clearance; DAPT, Dual antiplatelet therapy; DOAC, Direct oral anticoagulants; GIH, Gastrointestinal hemorrhage; IQR, Interquartile range; NSAID, Non-steroidal anti-inflammatory drug; SAPT, Single antiplatelet therapy

*Comparison between the appropriate and inappropriate dosing of direct oral anticoagulants by using the chi-squared test or Fisher's exact test (as appropriate) for proportions and the Mann-Whitney $U$ test for medians

**Fisher's exact test

registry conducted at a community practice in the US, demonstrated that an inappropriate dose of a DOAC was prescribed only in $12.5 \%(994 / 7925)$ of patients (underdosing in 9.3\% [734/7925] and overdosing in 3.3\% [260/7925] of patients, respectively) [9]. In a real-world registry in Spain, the rate of underdosing and overdosing of DOAC therapy was $17.5 \%(93 / 530)$ and $14.9 \%$ (79/ 530), respectively [16]. Other retrospective studies conducted abroad indicate that $5.4-17.4 \%$ patients are prescribed inappropriate reduced doses of DOACs (Additional file 1: Table S2) [17-20]. In our study, it was found that the rate of underdosing has been decreasing every year. This may be because the prescription rate of edoxaban has been increasing recently. For DOACs other than edoxaban, the appropriateness of dosing is evaluated by considering body weight as well as age and renal function. However, for edoxaban, doses may be determined only by body weight $(\leq 60 \mathrm{~kg})$; for example, in the case of a male patient, aged 65 years, with serum creatinine level of $0.8 \mathrm{mg} / \mathrm{dL}$ and body weight of $55 \mathrm{~kg}$ $(\mathrm{CrCl}$ of $72 \mathrm{~mL} / \mathrm{min})$, edoxaban meets the dose reduction criteria, whereas but the other DOACs do not. Therefore, the rate of appropriate reduced doses may be higher for edoxaban than those of the other DOACs, which shows that higher the prescription rate of edoxaban, lower the rate of underdosing.

Since the appropriateness of DOAC dosing was evaluated based on various dose reduction criteria, such as US Food and Drug Administration labeling, the European Heart Rhythm Association practical guide, summaries of product characteristics, and manufacturer labeling recommendations, the prevalence of the inappropriate dosing of DOACs also varied depending on the research. However, the prevalence of underdosing tends to be higher in comparison with overdosing in all past reports, which is consistent with the results of the current study. It is likely that anticoagulant therapies are under-prescribed by physicians because of the fear of increased bleeding $[3,4,21]$. In addition, the prevalence of DOAC underdosing in Japan appears to be higher than in other countries. This may be because Asians have been reported to have a higher risk of intracranial hemorrhage during anticoagulant therapy with warfarin than non-Asians [22], thus physicians in Japan may have greater concerns regarding bleeding risk. Sato et al. revealed that the HAS-BLED score, which is a practical risk score for estimating the risk for major bleeding in AF patients, is an independent predictor of underdosing for apixaban (OR 1.59, 95\% CI 1.18-2.13) and rivaroxaban (OR 2.27, 95\% CI 1.51-3.39) [7]. This is in accordance with our results that the inappropriate dosing of DOACs was significantly associated with higher HASBLED scores (OR 1.87, 95\% CI 1.42-2.51). In this study, a total of 20 cardiologists prescribed DOACs; however, the risk of stroke or hemorrhage in the patients varied for each physician (Additional file 1: Table S3), with the prevalence of inappropriate dosing also varying among physicians (Additional file 2: Figure S1). Guidelines for determining the recommended dose of DOACs taking into account real-world data are needed in the future.

Interestingly, our results demonstrated that the inappropriate dosing of DOACs was significantly higher in prescriptions for outpatients (vs. inpatients; OR 2.87, 95\% CI 1.53-5.62, $p<0.001$ ). For outpatients, there are two types of prescriptions in Japan: one is an out-ofhospital prescription for a community pharmacy and the other is an in-hospital prescription for the pharmacy inside the hospital. Recently, in Japan, more than $70 \%$ of

Table 4 Factors associated with the inappropriate dosing of direct oral anticoagulants in multivariate analysis

\begin{tabular}{llll}
\hline Predictor variables & Odds ratio & $95 \%$ confidence interval & $P$ value \\
\hline Outpatients (vs. inpatients) & 2.87 & $1.53-5.62$ & $<0.001$ \\
HAS-BLED score* & 1.87 & $1.42-2.51$ & $<0.001$
\end{tabular}

*Odds ratio per point increase

Type of hospital visit (outpatients or inpatients), history of bleeding, myocardial infarction, cerebrovascular disease, polypharmacy, single antiplatelet therapy, $\mathrm{CHADS}_{2}$ score, $\mathrm{CHA}_{2} \mathrm{DS}_{2}-\mathrm{VASc}$ score, and HAS-BLED score, which were factors associated $(p<0.1)$ with inappropriate direct oral anticoagulant prescription in univariate analysis, were included in multivariate logistic regression analysis with a stepwise procedure 
the outpatients receive out-of-hospital prescriptions; this rate is over $95 \%$ at our hospital. For outpatients, the DOACs were all prescribed as out-of-hospital prescriptions during the study period. For inpatients, the physician's prescription is audited by hospital pharmacists, and if the dose of the DOAC is considered inappropriate (i.e., underdosing or overdosing) in view of renal function, age, body weight, concomitant drug use, or other patient characteristics, a direct inquiry is performed by the hospital pharmacist. In contrast, for outpatients, there are few hospitals in Japan in which relevant clinical laboratory data are attached to out-of-hospital prescriptions, and community pharmacists generally cannot access these records. Since no laboratory data are displayed on the out-of-hospital prescriptions in our hospital, it is possible that adequate audits of community pharmacists for DOAC prescriptions have not been performed. This may be the reason why a greater proportion of inappropriate DOAC dosing was observed in outpatients compared with inpatients. In Japan, it has been reported that clinical laboratory data printed on out-of-hospital prescriptions contributes to an increase in the number of inquiries from community pharmacists to physicians in hospitals, thus promoting the optimization of prescriptions [23, 24]. For example, when community pharmacists noticed that the PT-INR of patients taking warfarin was rising, or levofloxacin was prescribed at a standard dose to patients with renal dysfunction, they may suggest that the corresponding physician reduce the dose appropriately. However, as prescriptions prior to inquiries conducted by the hospital and community pharmacists could not be analyzed owing to the retrospective nature of this study, it is unclear to what extent the pharmacist's inquiries contribute to the appropriateness of the physician's prescription. Chertow GM et al. demonstrated that a computerized order entry system considering renal function may improve dosing appropriateness and reduce the length of stay in inpatients with renal insufficiency [25]. In addition, it has been recommended that pharmacists check the laboratory data of outpatients in order to optimize prescriptions and play a more active role in aiding physicians to make better decisions [8]. In the future, further investigation of whether displaying the laboratory data on out-of-hospital prescriptions contributes to patient outcomes is warranted.

There are several limitations of this study that should be mentioned. First, this study was a retrospective, single-center pilot study, focused on prescriptions by only cardiologists in a Japanese university hospital. It is possible that prescriptions by non-cardiologists (e.g., brain surgeons) may have a lower rate of inappropriate DOAC dosing because they may also consider the risk of cerebral infarction rather than that of bleeding.
Second, although we could extract clinical data at the time of the initial DOAC prescription, the number of patients who were continuously followed up at our hospital was not enough to investigate the association between the inappropriate dosing of DOACs and subsequent clinical outcome. As the association between the appropriateness of DOAC dosing and clinical outcomes among the four DOACs is still controversial, further studies are needed to clarify the effectiveness and safety of DOAC dosing considering real-world clinical data. Third, we could not investigate the factors associated with the inappropriate dosing of each DOAC despite differences in the dose reduction criteria of the four DOACs because of the relatively small number of patients. In the future, a multicenter study will be necessary to obtain an adequate sample size of patients to conduct similar studies in each DOAC group.

In conclusion, our results demonstrated that an inappropriate dose of a DOAC was prescribed in approximately $20 \%$ of AF patients, and occurred more frequently in outpatients (vs. inpatients) and in patients with a higher risk of bleeding. It is recommended that pharmacists play a greater role in assisting in the prescription process in order to help physicians make better decisions. In the future, it may be necessary to introduce a system that allows patient data, such as clinical laboratory data, to be reviewed at community pharmacies.

\section{Supplementary information}

Supplementary information accompanies this paper at https://doi.org/10. 1186/s40780-020-0157-z.

Additional file1: Table S1. Comparison of demographic characteristics among the 4 groups, underdosing, appropriate reduced dosing, overdosing, and appropriate standard dosing of direct oral anticoagulants. Table S2. Appropriateness of direct oral anticoagulants in previous published reports. Table S3. Distributions (\%) of the risk scores for stroke or hemorrhage in patients by each physician who initiated direct oral anticoagulant therapy for more than 10 patients in the study period.

Additional file 2: Figure S1. Appropriateness of direct oral anticoagulant dosing for each cardiologist

\section{Abbreviations}

AF: Atrial fibrillation; CrCl: Creatinine clearance; DOAC: Direct oral anticoagulant; GIH: Gastrointestinal hemorrhage; PT-INR: Prothrombin timeinternational normalized ratio

\section{Acknowledgments}

We sincerely appreciate the help of the following doctors: Kunihiro Matsuo, Satoshi Etoh, Yosuke Takamiya, Yuiko Yano, Tetsu Okuda, and Sayaka Shimizu. We would like to thank Enago, Crimson Interactive Pvt. Ltd., for English language editing.

Author's contributions

$M M, H U$, and $\mathrm{Ol}$ contributed to the concept and design of the study; MM, YS, MM, MU, and KT conducted the study; MM, YN, KM, SA, and TY were involved in data analysis and interpretation of the results; MM drafted the manuscript; SJ, KO, KS, and HU supervised the entire project and reviewed 
the manuscript; All the authors have read and approved the final version of the manuscript.

\section{Funding}

There are no funding sources for this study.

\section{Availability of data and materials}

All data generated or analyzed during this study are included in this published article and its Supplementary information files.

\section{Ethics approval and consent to participate}

The Fukuoka University-Medical Ethics Review Board approved the study protocol (approval number R17-059) and waived the requirement to obtain written informed consent from the patients because of the retrospective nature of the study. All methods were performed in accordance with the relevant guidelines and regulations.

\section{Consent for publication}

Not applicable.

\section{Competing interests}

The author(s) declare no competing interests.

\section{Author details}

'Department of Pharmacy, Fukuoka University Chikushi Hospital, Fukuoka Japan; 1-1-1, Zokumyoin, Chikushino-shi, Fukuoka 818-8502, Japan. ${ }^{2}$ Department of Emergency and Critical Care Medicine, Faculty of Medicine, Fukuoka University, Fukuoka, Japan; 7-45-1, Nanakuma, Jonan-ku, Fukuoka 814-0180, Japan. ${ }^{3}$ Central Laboratory for Pathology and Morphology, Faculty of Medicine, Fukuoka University, Fukuoka, Japan; 7-45-1, Nanakuma, Jonan-ku, Fukuoka 814-0180, Japan. ${ }^{4}$ Department of Cardiovascular Diseases, Fukuoka University Chikushi Hospital, Fukuoka, Japan; 1-1-1, Zokumyoin, Chikushino-shi, Fukuoka 818-8502, Japan.

\section{Received: 6 November 2019 Accepted: 20 January 2020}

Published online: 11 February 2020

\section{References}

1. Inoue H, Fujiki A, Origasa H, Ogawa S, Okumura K, Kubota I, et al. Prevalence of atrial fibrillation in the general population of Japan: an analysis based on periodic health examination. Int J Cardiol. 2009;137:102-7.

2. Ruff CT, Giugliano RP, Braunwald E, Hoffman EB, Deenadayalu N, Ezekowitz $M D$, et al. Comparison of the efficacy and safety of new oral anticoagulants with warfarin in patients with atrial fibrillation: a meta-analysis of randomised trials. Lancet. 2014;383:955-62.

3. Sen S, Dahlberg KW. Physician's fear of anticoagulant therapy in nonvalvular atrial fibrillation. Am J Med Sci. 2014;348:513-21.

4. Ding M, Fratiglioni L, Johnell K, Fastbom J, Ljungdahl M, Qiu C. Atrial fibrillation and use of antithrombotic medications in older people: a population-based study. Int J Cardiol. 2017;249:173-8.

5. Yamashita $Y$, Uozumi R, Hamatani $Y$, Esato M, Chun $Y H$, Tsuji $H$, et al. Status and outcomes of direct Oral anticoagulant use in real-world atrial fibrillation patients - Fushimi AF registry. Circ J. 2017:81:1278-85.

6. Murata N, Okumura Y, Yokoyama K, Matsumoto N, Tachibana E, Kuronuma $\mathrm{K}$, et al. Clinical outcomes of off-label dosing of direct Oral anticoagulant therapy among Japanese patients with atrial fibrillation identified from the SAKURA AF registry. Circ J. 2019;83:727-35.

7. Sato T, Aizawa Y, Fuse K, Fujita S, Ikeda Y, Kitazawa H, et al. The comparison of inappropriate-low-doses use among 4 direct Oral anticoagulants in patients with atrial fibrillation: from the database of a single-center registry. J Stroke Cerebrovasc Dis. 2018;27:3280-8.

8. Schiff GD, Klass D, Peterson J, Shah G, Bates DW. Linking laboratory and pharmacy: opportunities for reducing errors and improving care. Arch Intern Med. 2003;163:893-900.

9. Steinberg BA, Shrader P, Pieper K, Thomas L, Allen LA, Ansell J, et al. Frequency and outcomes of reduced dose non-vitamin $\mathrm{K}$ antagonist anticoagulants: results from ORBIT-AF II (the outcomes registry for better informed treatment of atrial fibrillation II). J Am Heart Assoc. 2018. https:// doi.org/10.1161/JAHA.117.007633.

10. Cockcroft DW Gault MH. Prediction of creatinine clearance from serum creatinine. Nephron. 1976;16:31-41.
11. Kojima T, Akishita M, Kameyama Y, Yamaguchi K, Yamamoto H, Eto M, et al. High risk of adverse drug reactions in elderly patients taking six or more drugs: analysis of inpatient database. Geriatr Gerontol Int. 2012;12:761-2.

12. Gage BF, Waterman AD, Shannon W, Boechler M, Rich MW, Radford MJ. Validation of clinical classification schemes for predicting stroke: results from the National Registry of atrial fibrillation. JAMA. 2001;285:2864-70.

13. Lip GY, Nieuwlaat R, Pisters R, Lane DA, Crijns HJ. Refining clinical risk stratification for predicting stroke and thromboembolism in atrial fibrillation using a novel risk factor-based approach: the euro heart survey on atrial fibrillation. Chest. 2010;137:263-72.

14. Pisters R, Lane DA, Nieuwlaat R, de Vos CB, Crijns HJ, Lip GY. A novel userfriendly score (HAS-BLED) to assess 1-year risk of major bleeding in patients with atrial fibrillation: the euro heart survey. Chest. 2010;138:1093-100.

15. Okumura Y, Yokoyama K, Matsumoto N, Tachibana E, Kuronuma K, Oiwa K, et al. Current use of direct oral anticoagulants for atrial fibrillation in Japan: findings from the SAKURA AF registry. J Arrhythm. 2017:33:289-96.

16. Ruiz Ortiz M, Muñiz J, Raña Míquez P, Roldán I, Marín F, Asunción EstevePastor $\mathrm{M}$, et al. Inappropriate doses of direct oral anticoagulants in realworld clinical practice: prevalence and associated factors. A subanalysis of the FANTASIIA registry. Europace. 2018;20:1577-83.

17. Lavoie K, Turgeon MH, Brais C, Larochelle J, Blais L, Farand $\mathrm{P}$, et al. Inappropriate dosing of direct oral anticoagulants in patients with atrial fibrillation. J Atr Fibrillation. 2016;9:1478

18. McAlister FA, Garrison S, Kosowan L, Ezekowitz JA, Singer A. Use of direct Oral anticoagulants in Canadian primary care practice 2010-2015: a cohort study from the Canadian primary care sentinel surveillance network. J Am Heart Assoc. 2018. https://doi.org/10.1161/JAHA.117.007603.

19. Moudallel S, Steurbaut S, Cornu P, Dupont A. Appropriateness of DOAC prescribing before and during hospital admission and analysis of determinants for inappropriate prescribing. Front Pharmacol. 2018;9:1220.

20. Jacobs MS, van Hulst M, Campmans Z, Tieleman RG. Inappropriate nonvitamin $\mathrm{K}$ antagonist oral anticoagulants prescriptions: be cautious with dose reductions. Neth Heart J. 2019;27:371-7.

21. Andrade JG, Krahn AD, Skanes AC, Purdham D, Ciaccia A, Connors S. Values and preferences of physicians and patients with Nonvalvular atrial fibrillation who receive Oral anticoagulation therapy for stroke prevention. Can J Cardiol. 2016:32:747-53.

22. Shen AY, Yao JF, Brar SS, Jorgensen MB, Chen W. Racial/ethnic differences in the risk of intracranial hemorrhage among patients with atrial fibrillation. J Am Coll Cardiol. 2007;50:309-15.

23. Igarashi T, Kodawara T, Konno A, Kamitani Y, Watanabe K, Uno M, et al. Usability Assessment of Laboratory Data Printed on the Prescription for Outpatients. Iryo Yakugaku (Japanese Journal of Pharmaceutical Health Care and Sciences). 2014:40:530-536.

24. Sano A, Suetsugu K, Hata K, Fukisako M, Katayama M, Tanaka R, et al. Analysis of Questions on Out-of-hospital Prescriptions Related to Laboratory Data. Iryo Yakugaku (Japanese Journal of Pharmaceutical Health Care and Sciences). 2018:44:229-235.

25. Chertow GM, Lee J, Kuperman GJ, Burdick E, Horsky J, Seger DL, et al. Guided medication dosing for inpatients with renal insufficiency. JAMA. 2001:286:2839-44

\section{Publisher's Note}

Springer Nature remains neutral with regard to jurisdictional claims in published maps and institutional affiliations.

Ready to submit your research? Choose BMC and benefit from:

- fast, convenient online submission

- thorough peer review by experienced researchers in your field

- rapid publication on acceptance

- support for research data, including large and complex data types

- gold Open Access which fosters wider collaboration and increased citations

- maximum visibility for your research: over $100 \mathrm{M}$ website views per year

At $\mathrm{BMC}$, research is always in progress.

Learn more biomedcentral.com/submissions 